Author affiliations appear at the end of this article.

Published online ahead of print at www.jco.org on September 29, 2014

Written on behalf of the $\mathrm{NCIC}$ Clinical Trials Group and the Gruppo Italiano por lo Studio dei Linfomi.

tDeceased

Supported by Grants No. 015469 and 021039 from the Canadian Cancer Society Research Institute, and by Roche Canada and Eli Lilly Canada.

Presented in part at the Annual Meeting of the American Society of Hematology, Atlanta, GA, December 7-10, 2013, and the International Conference on Malignant Lymphoma, Lugano, Switzerland, June 19-22, 2013

Authors' disclosures of potential conflicts of interest and author contributions are found at the end of this article.

Clinical trial information: NCT00078949. Corresponding author: Michael Crump MD, Princess Margaret Cancer Centre 610 University Ave, Rm 5-209, Toronto, Ontario, Canada M5G 2M9; e-mail:

michael.crump@uhn.on.ca.

(c) 2014 by American Society of Clinical Oncology

0732-183X/14/3231w-3490w/\$20.00 DOI: 10.1200/JCO.2013.53.9593

\title{
Randomized Comparison of Gemcitabine, Dexamethasone, and Cisplatin Versus Dexamethasone, Cytarabine, and Cisplatin Chemotherapy Before Autologous Stem-Cell Transplantation for Relapsed and Refractory Aggressive Lymphomas: NCIC-CTG LY.12
}

Michael Crump, John Kuruvilla, Stephen Couban, David A. MacDonald, Vishal Kukreti, C. Tom Kouroukis, Morel Rubinger, † Rena Buckstein, Kevin R. Imrie, Massimo Federico, Nicola Di Renzo, Kang Howson-Jan, Tara Baetz, Leonard Kaizer, Michael Voralia, Harold J. Olney, A. Robert Turner, Jonathan Sussman, Annette E. Hay, Marina S. Djurfeldt, Ralph M. Meyer, Bingshu E. Chen, and Lois E. Shepherd

See accompanying editorial on page 3472

$$
\begin{array}{llllllll}
\text { A } & \text { B } & \text { S } & \text { T } & \text { R } & \text { A } & \text { C } & \text { T }
\end{array}
$$

\section{Purpose}

For patients with relapsed or refractory aggressive lymphoma, we hypothesized that gemcitabinebased therapy before autologous stem-cell transplantation (ASCT) is as effective as and less toxic than standard treatment.

\section{Patients and Methods}

We randomly assigned 619 patients with relapsed/refractory aggressive lymphoma to treatment with gemcitabine, dexamethasone, and cisplatin (GDP) or to dexamethasone, cytarabine, and cisplatin (DHAP). Patients with B-cell lymphoma also received rituximab. Responding patients proceeded to stem-cell collection and ASCT. Coprimary end points were response rate after two treatment cycles and transplantation rate. The noninferiority margin for the response rate to GDP relative to DHAP was set at $10 \%$. Secondary end points included event-free and overall survival, treatment toxicity, and quality of life.

\section{Results}

For the intention-to-treat population, the response rate with GDP was $45.2 \%$; with DHAP the response rate was $44.0 \%(95 \% \mathrm{Cl}$ for difference, $-9.0 \%$ to $6.7 \%)$, meeting protocol-defined criteria for noninferiority of GDP $(P=.005)$. Similar results were obtained in a per-protocol analysis. The transplantation rates were $52.1 \%$ with GDP and $49.3 \%$ with DHAP $(P=.44)$. At a median follow-up of 53 months, no differences were detected in event-free survival (HR, 0.99; stratified log-rank $P=.95)$ or overall survival (HR, 1.03; $P=.78)$ between GDP and DHAP. Treatment with GDP was associated with less toxicity $(P<.001)$ and need for hospitalization $(P<.001)$, and preserved quality of life $(P=.04)$.

\section{Conclusion}

For patients with relapsed or refractory aggressive lymphoma, in comparison with DHAP, treatment with GDP is associated with a noninferior response rate, similar transplantation rate, event-free survival, and overall survival, less toxicity and hospitalization, and superior quality of life.

\section{J Clin Oncol 32:3490-3496. (c) 2014 by American Society of Clinical Oncology}

\section{INTRODUCTION}

For patients with aggressive-histology lymphoma who experience disease progression during or after primary treatment, the combination of high-dose chemotherapy and autologous stem-cell transplantation (ASCT) remains the only curative option. Before proceeding to this therapy, sensitivity to second-line chemotherapy, as indicated by meeting treatment response criteria, is a prerequisite. ${ }^{1,2}$ Second-line treatment with dexamethasone, highdose cytarabine, and cisplatin (DHAP) is considered a standard chemotherapy regimen but is associated with substantial treatment-related toxicity. ${ }^{1}$ A phase II trial conducted by our group suggested that treatment with gemcitabine, dexamethasone, and cisplatin (GDP) could be administered safely in an outpatient setting, was well tolerated, efficacious, 
and did not interfere with the ability to collect peripheral blood stem cells. ${ }^{3,4}$ We thus hypothesized that treatment with GDP before highdose chemotherapy and ASCT would be as effective and associated with less morbidity compared with DHAP.

\section{PATIENTS AND METHODS}

\section{Study Oversight}

The NCIC Clinical Trials Group (CTG) LY.12 study was a randomized controlled trial conducted in 26 Canadian centers, 10 American centers, and one Australian center, and, in collaboration with the Gruppo Italiano Studio Linfomi (GISL), 18 centers in Italy. We designed this trial to compare GDP with DHAP as second-line chemotherapy before ASCT (first random assignment) and to evaluate the efficacy of post-transplantation treatment with the anti-CD20 antibody rituximab (second random assignment). The results of the first random assignment are the subject of this report. The LY.12 protocol was designed by the NCIC CTG Lymphoma Committee. The trial was approved by the research ethics boards of all participating centers, and written informed consent was provided by all participants. An independent data and safety monitoring committee monitored the trial at confidential meetings every 6 months and evaluated data that were provided at the two interim analyses. The NCIC CTG office in Kingston, Ontario, Canada, was responsible for data management and statistical analysis. The NCIC CTG conducted this trial with financial support obtained with a grant from the Canadian Cancer Society Research Institute. Financial support and supply of gemcitabine were provided by Eli Lilly; rituximab was provided by Roche Canada. The trial was independently designed, conducted, and analyzed by the NCIC CTG.

\section{Treatment Protocol}

Eligible patients were age 18 years or older, with aggressive-histology lymphoma according to the WHO classification. ${ }^{5}$ The histologic diagnosis, including determination of T- or B-cell lineage by immunohistochemistry, was documented by biopsy before initial therapy or at relapse and confirmed by a local reference pathologist. Patients with diffuse large B-cell lymphoma (DLBCL, including variants), peripheral T-cell lymphoma, and anaplastic large-cell lymphoma were required to have received previous treatment with one anthracycline-containing chemotherapy regimen. Patients with DLBCL arising from a background of follicular or other indolent-histology lymphoma

\begin{tabular}{|c|c|c|c|}
\hline \multicolumn{2}{|c|}{$\begin{array}{l}\text { Random assignment } \\
\qquad(\mathrm{N}=619)\end{array}$} & & \\
\hline \multicolumn{2}{|l|}{$\begin{array}{l}\text { Assigned to GDP (ITT population) } \\
\qquad(\mathrm{n}=310)\end{array}$} & \multicolumn{2}{|c|}{$\begin{array}{l}\text { Assigned to DHAP (ITT population) } \\
\qquad(n=309)\end{array}$} \\
\hline \multirow{2}{*}{\multicolumn{2}{|c|}{$\begin{array}{ll}\text { Eligible but not treated } & (n=3) \\
\text { Ineligible and treated } & (n=4)\end{array}$}} & \multirow{2}{*}{\multicolumn{2}{|c|}{$\begin{array}{ll}\text { Eligible but not treated } & (n=4) \\
\text { Ineligible and treated } & (n=2) \\
\text { Ineligible and not treated }(n=1)\end{array}$}} \\
\hline & & & \\
\hline \multicolumn{2}{|c|}{$\begin{array}{l}\text { Received at least one cycle of salvage } \\
\text { chemotherapy (PPP) } \\
\qquad(n=303)\end{array}$} & \multicolumn{2}{|c|}{$\begin{array}{l}\text { Received at least one cycle of salvage } \\
\text { chemotherapy (PPP) } \\
\qquad(n=302)\end{array}$} \\
\hline \multirow{8}{*}{$\begin{array}{l}\text { Discontinued protocol treatment } \\
\text { before ASCT } \\
\text { Died } \\
\text { Progressive disease } \\
\text { Insufficient response } \\
\text { Intercurrent illness } \\
\text { Toxicity } \\
\text { Received more than three cycles of } \\
\text { chemotherapy } \\
\text { Patient refusal }\end{array}$} & $(n=112)$ & \multirow{9}{*}{$\begin{array}{l}\text { Discontinued protocol treatment } \\
\text { before ASCT } \\
\text { Died } \\
\text { Progressive disease } \\
\text { Insufficient response } \\
\text { Intercurrent illness } \\
\text { Toxicity } \\
\text { Received more than three cycles of } \\
\text { chemotherapy } \\
\text { Patient refusal } \\
\text { Lost to follow-up } \\
\text { Completed ASCT after clinical } \\
\text { cutoff date }\end{array}$} & \multirow{9}{*}{$\begin{array}{r}(n=127) \\
(n=6) \\
(n=87) \\
(n=18) \\
(n=1) \\
(n=9) \\
(n=3) \\
\\
(n=1) \\
(n=1) \\
(n=1)\end{array}$} \\
\hline & $(n=4)$ & & \\
\hline & $(n=78)$ & & \\
\hline & $(n=17)$ & & \\
\hline & $(n=2)$ & & \\
\hline & $(n=5)$ & & \\
\hline & $(n=3)$ & & \\
\hline & $(n=3)$ & & \\
\hline & & & \\
\hline \multicolumn{2}{|l|}{$\begin{array}{l}\text { Attempted ASCT } \\
\qquad(\mathrm{n}=191)\end{array}$} & \multicolumn{2}{|l|}{$\begin{array}{l}\text { Attempted ASCT } \\
\qquad(\mathrm{n}=175)\end{array}$} \\
\hline \multirow{7}{*}{$\begin{array}{l}\text { Did not complete ASCT } \\
\text { Progressive disease } \\
\text { Intercurrent illness } \\
\text { Toxicity } \\
\text { Insufficient stem cell collection } \\
\text { Alternative therapy at investigator } \\
\text { discretion } \\
\text { Unknown complication }\end{array}$} & $(n=33)$ & \multirow{7}{*}{$\begin{array}{l}\text { Did not complete ASCT } \\
\text { Died } \\
\text { Progressive disease } \\
\text { Intercurrent illness } \\
\text { Insufficient stem cell collection } \\
\text { Alternative therapy at investigator } \\
\text { discretion } \\
\text { Claustrophobia }\end{array}$} & $(n=26)$ \\
\hline & $(n=19)$ & & $(n=1)$ \\
\hline & $(n=3)$ & & $(n=13)$ \\
\hline & $(n=1)$ & & $(n=2)$ \\
\hline & $(n=6)$ & & $(n=7)$ \\
\hline & $(n=3)$ & & $(n=2)$ \\
\hline & $(n=1)$ & & $(n=1)$ \\
\hline \multicolumn{2}{|l|}{$\begin{array}{l}\text { Completed ASCT } \\
\qquad(\mathrm{n}=158)\end{array}$} & \multicolumn{2}{|l|}{$\begin{array}{l}\text { Completed ASCT } \\
\qquad(\mathrm{n}=149)\end{array}$} \\
\hline
\end{tabular}

Fig 1. CONSORT diagram for $\mathrm{NCIC}$ Clinical Trials Group study LY.12. The intention-to-treat population (ITT) included all randomly assigned patients. The perprotocol (as treated) population (PPP) included all eligible patients who received at least one cycle of assigned protocol therapy. ASCT, autologous stem-cell transplantation; DHAP, dexamethasone, cytarabine, and cisplatin; GDP, gemcitabine, dexamethasone, and cisplatin. 
were eligible provided that they had received no more than three previous treatment regimens, with at least one regimen including an anthracycline. Baseline assessments included physical examination, standard laboratory testing, computed tomography (CT) scanning of the chest, abdomen, and pelvis, bone marrow biopsy, and, if indicated, CSF analysis (Data Supplement). Eligible patients were required to have measurable disease by CT scan or physical examination, an Eastern Cooperative Oncology Group performance status ${ }^{6}$ of 0 to 3 , and acceptable hematologic and biochemical parameters. Patients were excluded if they had previously received treatment with cisplatin, cytarabine, or gemcitabine, had CNS involvement with lymphoma, history of HIV infection, or a medical condition that would interfere with the safe delivery of the protocol chemotherapy.

Patients were stratified by treating center, International Prognostic In$\mathrm{dex}^{7}$ risk factors at trial entry, immunophenotype (B cell $v \mathrm{~T}$ cell), response to primary therapy (refractory, relapse at $\leq 1$ year, or relapse at $>1$ year) and previous rituximab treatment, and a concealed random assignment process ${ }^{8}$ using a computer-generated minimization procedure was performed to allocate patients with equal probabilities to the experimental (GDP) or control (DHAP) group. Two cycles of protocol therapy were administered at 21-day intervals and consisted of either intravenous gemcitabine $1,000 \mathrm{mg} / \mathrm{m}^{2}$ of body surface area per day on days 1 and 8 and cisplatin $75 \mathrm{mg} / \mathrm{m}^{2}$ on day 1 , and oral dexamethasone $40 \mathrm{mg}$ per day on days 1 through 4 (GDP); or oral dexamethasone $40 \mathrm{mg}$ per day on days 1 through 4 and intravenous cytarabine $2 \mathrm{~g} / \mathrm{m}^{2}$ over 3 hours once every 12 hours for two doses on day 2 and cisplatin 100 $\mathrm{mg} / \mathrm{m}^{2}$ by 24 -hour continuous infusion on day 1 (DHAP). Patients who had not achieved a complete or partial response after two treatment cycles were permitted to receive a third cycle of protocol therapy. The study was amended in November 2005 to provide patients with CD $20^{+}$lymphoma treatment with rituximab $375 \mathrm{mg} / \mathrm{m}^{2}$ intravenously on day 1 of each treatment cycle before the administration of chemotherapy. Treatment with GDP was designed to be delivered to patients in an outpatient setting and included a recommended minimum hydration schedule for cisplatin. ${ }^{4}$ Dose attenuations for treatmentrelated toxicity were prescribed (Data Supplement). Patients with a positive test for hepatitis B surface antigen were recommended to be monitored for hepatitis B reactivation and to receive lamivudine. Primary prophylaxis against febrile neutropenia with granulocyte colony-stimulating factor was not mandated. Each participating center was responsible for determining policies for hematopoietic stem-cell mobilization, choice of high-dose chemotherapy regimen, supportive care after stem-cell reinfusion, and use of post-transplantation involved-field radiation to areas of bulky disease at relapse or progression.

\section{Assessment of Response and Definition of Study Outcomes}

Patients underwent disease re-evaluation after two and, if applicable, three cycles of protocol therapy. Imaging tests to evaluate remission status were repeated 3, 7, 13, and 25 months after stem-cell reinfusion and when clinically indicated. Response assessment was categorized according to the 1999 International Working Group criteria. ${ }^{9}$ Patients receiving a nonprotocol salvage chemotherapy regimen that was different from that allocated by random assignment were categorized as having an event and withdrawn from the study. The primary end point of response rate by arm after two cycles of treatment was calculated by considering the number of patients achieving a complete, unconfirmed complete, or partial response among those randomly assigned (intention-to-treat analysis) and among those eligible patients who received at least one cycle of protocol therapy (per-protocol analysis). An additional, post hoc, per-protocol analysis was performed that also excluded patients who were alive and without documented disease progression who were not evaluated after two cycles of treatment. The transplantation rate by arm was calculated by considering the number of patients categorized as achieving a response to therapy and meeting criteria for successful stem-cell mobilization (obtaining at least $2 \times 10^{6} \mathrm{CD} 34^{+}$cells/kg of body weight) among those receiving at least one cycle of assigned chemotherapy; a sensitivity analysis was performed that included all randomly assigned patients. Overall survival was calculated from the date of random assignment to date of death from any cause; event-free survival was calculated from the date of random assignment to the date of objective or symptomatic disease progression, relapse after objective response, initiation of new lymphoma therapy, or death from any cause. Event-free and overall survivals were evaluated using data from an intention-to-treat population. Adverse events were graded according to National Cancer Institute Common Toxicity Criteria version 2.0. ${ }^{10}$ Quality of life (QoL) was measured using the Functional Assessment of Cancer Therapy (FACT) instrument, ${ }^{11}$ including a subscale for neurologic toxicity and a lymphoma-specific subscale, ${ }^{12}$ and was assessed at baseline, end of cycle 1 , middle and end of cycle 2, and 1 month after stem-cell infusion. A change in a QoL item rating of $10 \%$ or more when compared with the baseline value was considered a clinically meaningful change.

\section{Statistical Analysis}

The primary objective associated with the first random assignment of the LY.12 trial was to test whether the response rate obtained after two cycles of GDP was noninferior to the response rate obtained with DHAP. If GDP was shown to be noninferior, the transplantation rates of GDP and DHAP would be evaluated for superiority of GDP. Secondary objectives included comparing GDP and DHAP with respect to event-free and overall survival, rates of successful stem-cell mobilization, frequency of adverse events, QoL, and resource usage. Assuming that the response rate obtained would be $50 \%$ with DHAP and 60\% with DHAP-rituximab, GDP would be considered noninferior if the one-sided upper $95 \%$ confidence limit for the difference in response

\begin{tabular}{|c|c|c|c|c|}
\hline \multirow[b]{2}{*}{ Characteristic } & \multicolumn{2}{|c|}{$\begin{array}{c}\text { GDP } \\
(n=310)\end{array}$} & \multicolumn{2}{|c|}{$\begin{array}{c}\text { DHAP } \\
(n=309)\end{array}$} \\
\hline & No. & $\%$ & No. & $\%$ \\
\hline \multicolumn{5}{|l|}{ Age, years } \\
\hline Median & \multicolumn{2}{|c|}{55.2} & \multicolumn{2}{|c|}{54.6} \\
\hline Range & \multicolumn{2}{|c|}{$18.7-71.2$} & \multicolumn{2}{|c|}{$22.6-74.3$} \\
\hline$>60$ & 88 & 29.4 & 89 & 28.8 \\
\hline \multicolumn{5}{|l|}{ Sex } \\
\hline Female & 122 & 39.4 & 118 & 38.2 \\
\hline Male & 188 & 60.6 & 191 & 61.8 \\
\hline \multicolumn{5}{|l|}{ ECOG performance status } \\
\hline 0 & 127 & 41.0 & 130 & 42.1 \\
\hline 1 & 141 & 45.5 & 137 & 44.3 \\
\hline$\geq 2$ & 42 & 13.5 & 42 & 13.6 \\
\hline \multicolumn{5}{|l|}{ Disease stage } \\
\hline III & 79 & 25.5 & 76 & 24.6 \\
\hline IV & 138 & 44.5 & 134 & 43.4 \\
\hline \multicolumn{5}{|l|}{ Immunophenotype } \\
\hline B & 277 & 89.4 & 277 & 89.6 \\
\hline T/null/NK & 33 & 10.6 & 32 & 10.4 \\
\hline \multicolumn{5}{|l|}{ Histology, lymphoma } \\
\hline Diffuse large B cell & 216 & 71 & 203 & 67 \\
\hline Transformed indolent & 42 & 14 & 45 & 15 \\
\hline Peripheral T cell & 12 & 4 & 15 & 5 \\
\hline Anaplastic large cell & 10 & 3 & 13 & 5 \\
\hline Primary mediastinal & 6 & 2 & 12 & 4 \\
\hline \multicolumn{5}{|l|}{ IPI risk factors at entry } \\
\hline 0,1 & 115 & 38 & 117 & 38 \\
\hline 2 & 88 & 29 & 89 & 29 \\
\hline$\geq 3$ & 100 & 33 & 98 & 32 \\
\hline \multicolumn{5}{|l|}{ Response to previous treatment } \\
\hline Complete response $\geq 1$ year & 81 & 27 & 83 & 27 \\
\hline Complete response $<1$ year & 129 & 42 & 128 & 41 \\
\hline No response/progressive disease & 95 & 31 & 94 & 30 \\
\hline \multicolumn{5}{|l|}{ Previous therapy including } \\
\hline Radiation & 76 & 25 & 73 & 24 \\
\hline Rituximab & 205 & 67 & 205 & 67 \\
\hline
\end{tabular}

Abbreviations: DHAP, dexamethasone, cytarabine, cisplatin; ECOG, Eastern Cooperative Oncology Group; GDP, gemcitabine, dexamethasone, cisplatin; IPI, International Prognostic Index; NK, natural killer. 
rate between the two arms was less than $10 \%$. To exclude a $10 \%$ difference with $80 \%$ power, 630 eligible patients were required. An interim analysis for futility around the noninferiority end point was planned after 320 patients were enrolled; the protocol was amended to add a second interim analysis after 480 patients were entered, resulting in a final sample size of 637 patients.

The $\chi^{2}$ test $^{13}$ was used to compare the rates of response, transplantation, adverse events, and successful stem-cell mobilization of the two treatment arms. The Kaplan and Meier ${ }^{14}$ life-table method was used to calculate eventfree and overall survivals, and groups were compared using the log-rank test ${ }^{15}$ with incorporation of the stratification factors used at random assignment. Using clinically important change score criteria, responses to each QoL item were categorized into improved, stable, and worse categories, and a $\chi^{2}$ test was performed to compare the distributions of these categories between the two treatment arms. ${ }^{16}$ All analyses were performed using SAS software, version 9.2 (SAS Institute, Cary, NC).

In October 2011, the trial committee recognized that more than 1 additional year of accrual would be needed to meet the planned sample size. A request was submitted to the data safety monitoring committee to allow closure of accrual; this was approved in November 2011.

\section{RESULTS}

\section{Patients}

From August 2003 to November 2011, we randomly assigned 619 patients. Seven patients were subsequently considered to be ineligible, and seven did not receive therapy according to their allocation; these 14 patients were equally distributed between the two arms (Fig 1). The median age of the patients was 55 years, and $28 \%$ were older than age 60 years. Most patients had stage III or IV and highintermediate or high-risk disease ${ }^{7}$ at random assignment, and had either not achieved a remission with initial therapy or had recurrence of lymphoma within 1 year of completing treatment. Seventy-one percent had DLBCL, $15 \%$ had lymphoma that had transformed from an indolent B-cell histology; 8\% had T-cell or anaplastic large-cell lymphoma. Among 554 patients with B-cell lymphoma, 411 had received rituximab as part of previous therapy (Table 1).

\section{Treatment Outcomes}

At least two cycles of protocol therapy were received by $90 \%$ of patients who were allocated to the GDP group (277 of 306 patients) and $87 \%$ of those who were allocated to the DHAP group (266 of 304 patients). In the intention-to-treat population, the rate of response after two cycles of treatment was $45.1 \%$ in the GDP group and $44.1 \%$ in the DHAP group $(P=.84)$. The upper boundary of the one-sided $95.6 \% \mathrm{CI}$ for the difference in response rates was $5.7 \%$, thus meeting the protocol-specified criterion for noninferiority of GDP compared with DHAP $(P=.005)$. The primary and post hoc per-protocol analyses also met criteria for noninferiority (Table 2). The transplantation rate was $52.1 \%$ in the GDP group and $49.3 \%$ in the DHAP group (difference between arms [DHAP-GDP], $-2.5 \%$; 95\% CI, $-10.5 \%$ to $5.5 \% ; P=.44$ ). Similar results were observed among the intention-to-treat population. The rate of successful stem-cell mobilization (defined as collection of $>2.0 \times 10^{6} \mathrm{CD} 34^{+}$cells $/ \mathrm{kg}$ ) was $87.9 \%$ in the GDP group and $82.2 \%$ in the DHAP group $(P=.14)$. Thirty-three patients treated with GDP and 26 patients receiving DHAP who were planned for transplantation on the basis of response to protocol therapy did not proceed to ASCT because of disease progression (GDP arm, 19 patients; DHAP arm, 13 patients) or inability to collect stem cells (GDP arm, six patients; DHAP arm, seven patients; Fig 1).

The median duration of follow-up was 53 months. No differences were detected in the 4-year event-free survival (HR, 0.99; 95\% $\mathrm{CI}, 0.82$ to 1.21 ; stratified $\log$-rank $P=.95$; Fig $2 \mathrm{~A}$ ) or overall survival (HR, 1.03; $95 \% \mathrm{CI}, 0.83$ to $1.28 ; P=.78$ ) of the GDP and DHAP groups, respectively (Fig $2 \mathrm{~B}$ ).

\begin{tabular}{|c|c|c|c|c|c|c|c|}
\hline \multirow[b]{2}{*}{ Outcome } & \multicolumn{2}{|c|}{ GDP } & \multicolumn{2}{|c|}{ DHAP } & \multirow[b]{2}{*}{$P$} & \multicolumn{2}{|c|}{ Difference (DHAP - GDP) } \\
\hline & No. & $\%$ & No. & $\%$ & & $\%$ & $95 \% \mathrm{Cl}$ \\
\hline \multicolumn{8}{|l|}{$\begin{array}{l}\text { Rate of response (CR, CRu, } \\
\text { (PR) }\end{array}$} \\
\hline Intention-to-treat populationt & \multicolumn{2}{|c|}{140 of 310} & \multicolumn{2}{|c|}{136 of 309} & \multirow[t]{4}{*}{$.005 \ddagger$} & \multirow[t]{4}{*}{-1.2} & \multirow[t]{4}{*}{-9.0 to 6.7} \\
\hline Overall RR & & 45.1 & & 44.1 & & & \\
\hline $\mathrm{CR} / \mathrm{CRu}$ & & 13.5 & & 14.3 & & & \\
\hline PR & & 31.6 & & 29.8 & & & \\
\hline Primary per-protocol analysis§ & \multicolumn{2}{|c|}{140 of 303} & \multicolumn{2}{|c|}{135 of 302} & \multirow[t]{4}{*}{$.004 \ddagger$} & \multirow[t]{4}{*}{-1.5} & \multirow[t]{4}{*}{-9.4 to 6.4} \\
\hline Overall RR & & 46.1 & & 44.7 & & & \\
\hline $\mathrm{CR} / \mathrm{CRu}$ & & 13.8 & & 14.6 & & & \\
\hline PR & & 32.3 & & 30.1 & & & \\
\hline $\begin{array}{l}\text { Sensitivity per-protocol } \\
\text { analysis } \|\end{array}$ & 140 of 287 & 48.8 & 135 of 284 & 47.5 & $.004 \ddagger$ & -1.3 & -9.4 to 7.0 \\
\hline \multicolumn{8}{|l|}{ Rate of transplantation } \\
\hline Intention-to-treat analysist & 158 of 310 & 51.0 & 151 of 309 & 48.9 & .559 & -2.1 & -10.0 to 5.8 \\
\hline Per-protocol analysis§ & 158 of 303 & 52.1 & 149 of 302 & 49.3 & .449 & -2.5 & -10.5 to 5.5 \\
\hline \multicolumn{8}{|c|}{$\begin{array}{l}\text { Abbreviations: CR, complete response; CRu, complete response unconfirmed; DHAP, dexamethasone, cytarabine, cisplatin; GDP, gemcitabine, dexamethasone, } \\
\text { cisplatin; PR, partial response; RR, response rate. } \\
\text { *Includes four patients assessed after one cycle who had durable responses (two PRs, one CRu, one CR). } \\
\text { †Based on } 619 \text { patients who were randomly assigned. } \\
\text { łFor noninferiority. } \\
\text { \$Based on } 605 \text { eligible patients who received at least one dose of assigned therapy. } \\
\text { \|Based on } 571 \text { eligible patients who received at least one dose of assigned therapy and were evaluable for response. } \\
\text { ๆFor superiority. }\end{array}$} \\
\hline
\end{tabular}




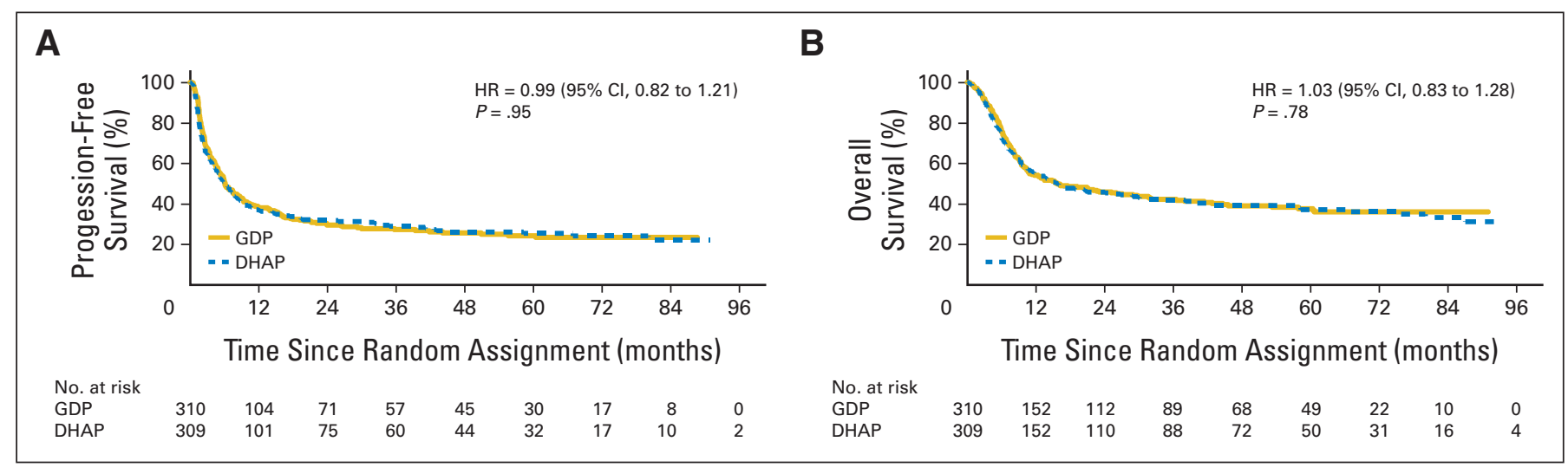

Fig 2. (A) Progression-free survival for patients randomly assigned to gemcitabine, dexamethasone, and cisplatin (GDP; gold line) or dexamethasone, cytarabine, and cisplatin (DHAP; blue dashed line). (B) Overall survival for patients randomly assigned to GDP (gold line) or DHAP (blue dashed line). HR, hazard ratio.

In the multivariable analysis stratified by prognostic variables used for random assignment, none of the following variables was predictive of overall response to salvage chemotherapy: treatment arm, age, performance status, stage III or IV disease, or number of extranodal sites of disease (Data Supplement). Only advancedstage disease was predictive of event-free survival, whereas advanced stage, poor performance status, and two or more extranodal sites were predictive of overall survival. Response rates according to stratification variables were similar and are shown in the Data Supplement.

\section{Adverse Events, QoL, and Supportive Care}

Eight patients died as a result of protocol treatment-related complications: two during treatment with GDP and six after receiving DHAP. Grade 3 or 4 adverse events were observed significantly less frequently during the first two cycles of chemotherapy among patients receiving GDP (47\% $v 61 \% ; P<.001)$, including fewer episodes of febrile neutropenia ( $9 \% v 23 \%$; $<<.001$; Table 3). QoL assessment, using FACT-Total scores, showed that, compared with baseline status, there was less deterioration among patients who were allocated to

\begin{tabular}{|c|c|c|c|c|c|}
\hline \multirow[b]{2}{*}{ Adverse Event } & \multicolumn{2}{|c|}{$\begin{array}{c}\text { GDP } \\
(n=306)\end{array}$} & \multicolumn{2}{|c|}{$\begin{array}{c}\text { DHAP } \\
(n=304)\end{array}$} & \multirow[b]{2}{*}{$P$} \\
\hline & No. & $\%$ & No. & $\%$ & \\
\hline Thrombosis/embolism & 18 & 6 & 18 & 6 & NS \\
\hline Fatigue & 30 & 10 & 28 & 9 & NS \\
\hline Nausea & 13 & 4 & 25 & 8 & .04 \\
\hline Vomiting & 22 & 7 & 21 & 7 & NS \\
\hline \multicolumn{6}{|l|}{ Infection } \\
\hline With grade 3 to 4 neutropenia & 18 & 6 & 28 & 9 & NS \\
\hline Without neutropenia & 21 & 7 & 22 & 7 & NS \\
\hline Febrile neutropenia & 28 & 9 & 70 & 23 & $<.001$ \\
\hline Syncope & 7 & 2 & 16 & 5 & \\
\hline Worst overall & 143 & 47 & 186 & 61 & $<.001$ \\
\hline \multicolumn{6}{|c|}{$\begin{array}{l}\text { NOTE. Comparison of most frequently occurring serious adverse events, } \\
\text { occurring in at least } 5 \% \text { of patients who received at least one dose of protocol } \\
\text { therapy, at grade } 3 \text { or } 4 \text { (National Cancer Institute Common Toxicity Criteria } \\
\text { version 2.0). } \\
\text { Abbreviations: DHAP, dexamethasone, cytarabine, cisplatin; GDP, gemcitabine, } \\
\text { dexamethasone, cisplatin; NS, not significant. }\end{array}$} \\
\hline
\end{tabular}

GDP, with significant differences observed at the end of the first cycle of treatment and at the midpoint of treatment cycle 2 (Fig 3A). At the midpoint of cycle 2, more patients receiving GDP had an improved clinically meaningful change score $(18 \% v 11 \%)$ and fewer had a worse clinically meaningful change score (33\% v 41\%; $P=.04$; Fig 3B) compared with those treated with DHAP. Patients allocated to GDP required fewer platelet transfusions ( $31 \% v 47 \% ; P<.001)$, including during the first two cycles of treatment $(18 \% v 32 \% ; P<.001)$. Fewer patients receiving GDP required hospitalization (47\% v 99\%; $P<$ $.001)$, which was consistent with the expectation that this treatment could be administered to outpatients; in addition, fewer patients randomly assigned to GDP required hospitalization for management of an adverse event or other illness $(18 \% v 30 \% ; P<.001)$.

\section{DISCUSSION}

Patients with aggressive lymphoma and disease progression or recurrence after primary chemotherapy experience superior overall survival when treated with high-dose chemotherapy and ASCT compared with continued treatment with standard doses of chemotherapy. ${ }^{1}$ Several second-line chemotherapy regimens that are designed to increase the proportion of patients eligible for transplantation through the use of more intense chemotherapy have been evaluated and are associated with substantial hematologic toxicity and considerable use of health care resources. ${ }^{17-19}$ At the time we initiated our study, no randomized trials comparing salvage chemotherapy regimens had been conducted. We tested the hypothesis that comparable efficacy could be achieved with GDP and that this treatment, administered on an outpatient basis, would be associated with fewer adverse events and less frequent hospitalization compared with DHAP.

Our trial is the largest randomized comparison of second-line chemotherapy regimens administered before autologous stem-cell transplantation, to our knowledge, and the results confirmed our hypothesis. We observed that the overall rate of response that was obtained with GDP was noninferior to DHAP and that GDP was associated with fewer grade 3 and 4 adverse events, including febrile neutropenia, less frequent need for hospitalization related to toxicity, reduced need for platelet transfusion support, and better preservation of patient-reported QoL. Having met the primary end point of the trial, we also assessed whether a greater number of patients would 


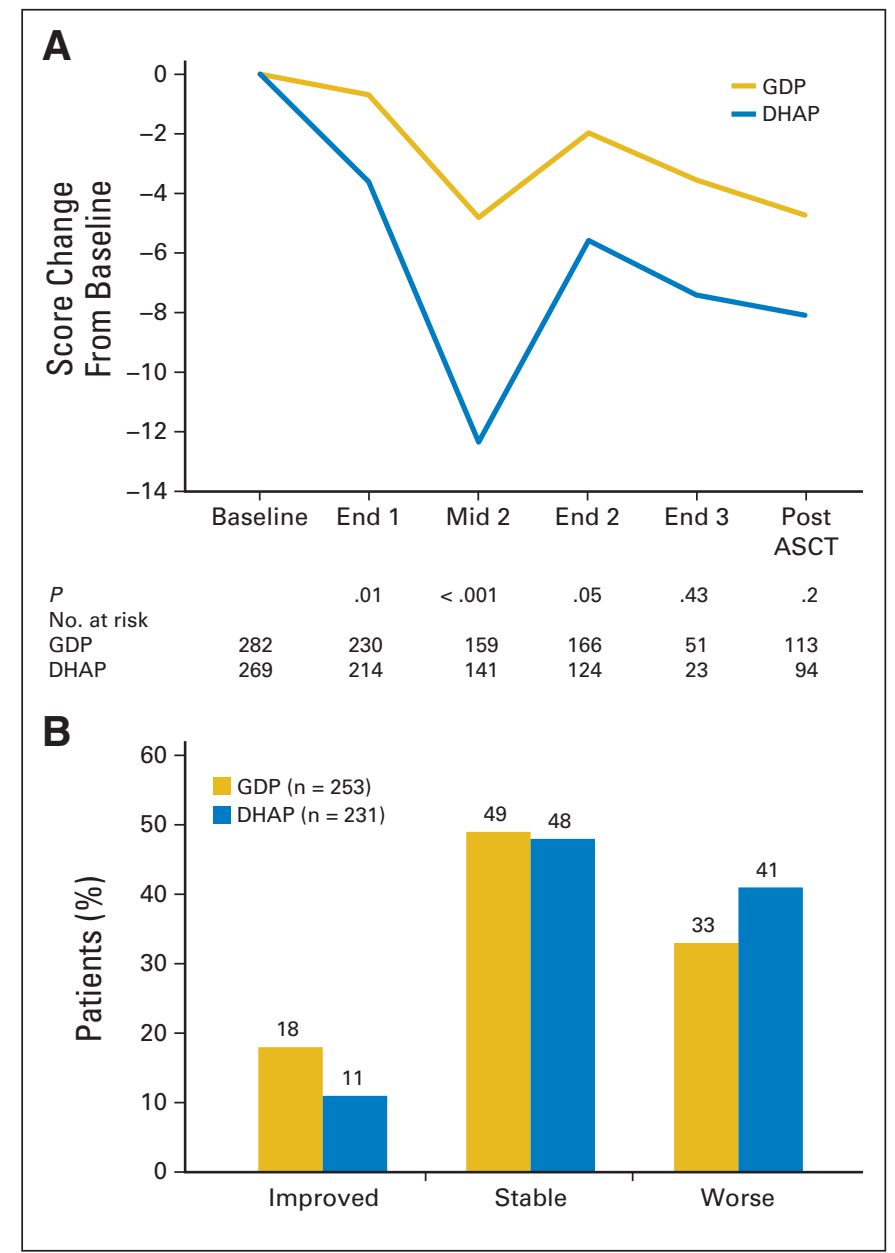

Fig 3. (A) Mean change in total Functional Assessment of Cancer Therapy-General (FACT-G) scores; significant differences were seen at the end of cycle 1 (End 1), the middle of cycle 2 (Mid 2), and the end of cycle 2 (End 2). (B) Percentage of patients reporting a minimally important difference in FACT-G total score of $10 \%$ or more, assessed at midpoint of cycle 2: more patients who received gemcitabine, dexamethasone, and cisplatin (GDP) experienced improvement in and fewer experienced deterioration in quality of life than those treated with dexamethasone, cytarabine, and cisplatin (DHAP). ASCT, autologous stem-cell transplantation.

proceed to transplantation if treated with GDP. Although this end point was not met, the proportions of patients achieving a stem-cell collection of $>2.0 \times 10^{6} \mathrm{CD}^{+} 4^{+}$peripheral blood stem cells $/ \mathrm{kg}$ $(87.9 \% \vee 82.2 \%)$ and proceeding to autologous transplantation $(52.1 \% \quad v 49.3 \%)$ seem to be similar with GDP and DHAP, respectively. Finally, no differences were detected in 4-year event-free ( $26 \%$ in each group) or overall survivals (39\% in each group).

We chose response to therapy as the primary end point for this study because sensitivity to chemotherapy is a fundamental prerequisite for proceeding to autologous transplantation. The response rate we observed seems to be less than that reported by Gisselbrecht et al, ${ }^{2}$ who compared rituximab plus DHAP with rituximab, ifosfamide, carboplatin, and etoposide. Eligibility for that trial was restricted to patients with DLBCL, whereas our study included patients with transformed indolent lymphoma and T-cell lymphoma. In addition, more than $70 \%$ of patients in our study either did not achieve a remission with primary therapy or experienced recurrence within 1 year of completing that therapy, factors that predict for a lower rate of response and poorer event-free survival. ${ }^{19}$ Nonetheless, the proportion of patients proceeding to transplantation in both studies was similar, as was overall survival after 3 years of follow-up. ${ }^{20}$ The proportion of patients event-free 4 years after transplantation was $53 \%$ in the study by Gisselbrecht et $\mathrm{al}^{21}$ which is similar to that observed in the current study (43\% for GDP and 49\% for DHAP; Data Supplement).

Outcomes after ASCT for patients with aggressive lymphoma have consistently been shown to be related to clinical variables that include International Prognostic Index risk factors ${ }^{22}$ and previous exposure to the CD20 antibody rituximab, ${ }^{20,23}$ in addition to histology and previous response duration. Recently, it has been recognized that germinal center B-cell and activated B-cell subtypes of DLBCL, defined by gene expression profiling, have distinct molecular origins and natural histories, which may also account for variability in outcomes after ASCT. ${ }^{24}$ An exploratory analysis by Thieblemont et $\mathrm{al}^{25}$ of immunohistochemical and molecular profiling of biopsies from patients who experienced relapse suggests that response to different salvage regimens may not be uniform between these subtypes of aggressive lymphoma, providing a potential avenue, if confirmed, for selective addition of agents that target these genetic differences. We are currently analyzing biopsy samples from patients who were enrolled onto our trial to determine if cell of origin and other molecular biomarkers are correlated with response and long-term outcomes.

In summary, for patients with relapsed or refractory aggressivehistology lymphoma, treatment with GDP before high-dose chemotherapy and ASCT is as effective as DHAP and is associated with fewer adverse events, less frequent need for hospitalization, and superior patient-reported QoL. This treatment can be considered the preferred treatment option for these patients.

\section{AUTHORS' DISCLOSURES OF POTENTIAL CONFLICTS OF INTEREST}

Although all authors completed the disclosure declaration, the following author(s) and/or an author's immediate family member(s) indicated a financial or other interest that is relevant to the subject matter under consideration in this article. Certain relationships marked with a " $U$ " are those for which no compensation was received; those relationships marked with a "C" were compensated. For a detailed description of the disclosure categories, or for more information about ASCO's conflict of interest policy, please refer to the Author Disclosure Declaration and the Disclosures of Potential Conflicts of Interest section in Information for Contributors. Employment or Leadership Position: None Consultant or Advisory Role: David A. MacDonald, Roche Canada (C); Ralph M. Meyer, Eli Lilly (C) Stock Ownership: None Honoraria: John Kuruvilla, Roche Canada; David A. MacDonald, Roche Canada; Tara Baetz, Roche Research Funding: Michael Crump, Roche Canada; John Kuruvilla, Roche Canada; David A. MacDonald, Roche Canada Expert Testimony: None Patents, Royalties, and Licenses: None Other Remuneration: None

\section{AUTHOR CONTRIBUTIONS}

Conception and design: Michael Crump, Kevin R. Imrie, Tara Baetz, A. Robert Turner, Jonathan Sussman, Ralph M. Meyer, Bingshu E. Chen, Lois E. Shepherd

Financial support: Lois E. Shepherd

Administrative support: Marina S. Djurfeldt, Ralph M. Meyer, Lois E. Shepherd 
Provision of study materials or patients: Michael Crump, John Kuruvilla, Stephen Couban, David A. MacDonald, Vishal Kukreti, C. Tom Kouroukis, Morel Rubinger, Rena Buckstein, Kevin R. Imrie, Massimo Federico, Nicola Di Renzo, Kang Howson-Jan, Tara Baetz, Leonard Kaizer, Michael Voralia, Harold J. Olney, A Robert Turner, Ralph M. Meyer

Collection and assembly of data: Michael Crump, John Kuruvilla, Stephen Couban, David A. MacDonald, Vishal Kukreti, C. Tom Kouroukis, Morel Rubinger, Rena Buckstein, Kevin R. Imrie, Massimo
Federico, Nicola Di Renzo, Kang Howson-Jan, Tara Baetz, Leonard Kaizer, Michael Voralia, Harold J. Olney, A Robert Turner, Annette E. Hay, Marina S. Djurfeldt, Ralph M. Meyer, Lois E. Shepherd Data analysis and interpretation: Michael Crump, Jonathan Sussman, Annette E. Hay, Marina S. Djurfeldt, Ralph M. Meyer, Bingshu E. Chen, Lois E. Shepherd

Manuscript writing: All authors

Final approval of manuscript: All authors

\section{REFERENCES}

1. Philip $T$, Guglielmi $C$, Hagenbeek $A$, et al: Autologous bone marrow transplantation as compared with salvage chemotherapy in relapses of chemotherapy-sensitive non-Hodgkin's lymphoma. N Engl J Med 333:1540-1545, 1995

2. Gisselbrecht C, Glass B, Mounier N, et al: Salvage regimens with autologous transplantation for relapsed large B-cell lymphoma in the rituximab era. J Clin Oncol 28:4184-4190, 2010

3. Baetz T, Belch A, Couban S, et al: Gemcitabine, dexamethasone and cisplatin is an active and non-toxic chemotherapy regimen in relapsed or refractory Hodgkin's disease: A phase II study by the National Cancer Institute of Canada Clinical Trials Group. Ann Oncol 14:1762-1767, 2003

4. Crump M, Baetz T, Couban S, et al: Gemcitabine, dexamethasone and cisplatin in patients with recurrent or refractory aggressive histology B-cell non-Hodgkin lymphoma: A phase II study by the National Cancer Institute of Canada Clinical Trials Group (NCIC-CTG). Cancer 101:1835-1842, 2004

5. Jaffe ES, Harris NL, Stein $H$, et al: WHO Classification of Tumours: Pathology and Genetics of Tumours of Haematopoietic and Lymphoid Tissues. Lyon, France, IARC Press, 2001

6. Oken MM, Creech RH, Tormey DC, et al: Toxicity and response criteria of the Eastern Cooperative Oncology Group. Am J Clin Oncol 5:649-655, 1982

7. [No authors listed]: A predictive model for aggressive non-Hodgkin's lymphoma: The International Non-Hodgkin's Lymphoma Prognostic Factors Project. N Engl J Med 329:987-994, 1993

8. White SJ, Freedman LS: Allocation of patients to treatments groups in a controlled clinical study. $\mathrm{Br}$ J Cancer 37:849-857, 1978
9. Cheson BD, Horning SJ, Coiffier B, et al: Report of an international workshop to standardize response criteria for non-Hodgkin's lymphomas: $\mathrm{NCl}$ Sponsored International Working Group. J Clin Oncol 17:1244-1253, 1999

10. National Cancer Institute Cancer Therapy Evaluation Program: Common Toxicity Criteria Version 2.0 ( $\mathrm{NCl}$ CTC v2.0). http://ctep.cancer.gov/ protocolDevelopment/electronic_applications/docs/ ctcv20_4-30-992.pdf

11. Cella DF, Tulsky DS, Gray G, et al: The Functional Assessment of Cancer Therapy scale: Development and validation of the general measure. J Clin Oncol 11:570-579, 1993

12. Eremenco $S$, Webster $K$, Kutikova $L$, et al: Development and multilingual validation of the FACT-Lymphoma Instrument. Qual Life Res 13: 1501, 2004 (abstr 1124)

13. Cochran WG: Some methods for strengthening the common $\chi^{2}$ tests. Biometrics 10:417-451, 1954

14. Kaplan EL, Meier P: Nonparametric estimation from incomplete observations. J Am Stat Assoc 53:457-481, 1958

15. Mantel N: Evaluation of survival data and two new rank order statistics arising in its consideration. Cancer Chemother Rep 50:163-170, 1966

16. Osoba D, Bezjak A, Brundage M, et al: Analysis and interpretation of health-related quality of life data from clinical trials: Basic approach of the $\mathrm{Na}$ tional Cancer Institute of Canada Clinical Trials Group. Eur J Cancer 41:280-287, 2005

17. Girouard C, Dufresne J, Imrie K, et al: Salvage chemotherapy with mini-BEAM for relapsed or refractory non-Hodgkin's lymphoma prior to autologous bone marrow transplantation. Ann Oncol 8:675-680, 1997

18. Jerkeman $M$, Leppä $S$, Kvaløy $S$, et al: ICE (ifosfamide, carboplatin, etoposide) as second-line chemotherapy in relapsed or primary progressive aggressive lymphoma: The Nordic Lymphoma Group experience. Eur J Haematol 73:179-182, 2004

19. Josting A, Sieniawski M, Glossmann JP, et al: High-dose sequential chemotherapy followed by autologous stem cell transplantation in relapsed and refractory aggressive non-Hodgkin's lymphoma: Results of a multicenter phase II study. Ann Oncol 16:1359-1365, 2005

20. Guglielmi C, Gomez F, Philip T, et al: Time to relapse has prognostic value in patients with aggressive lymphoma enrolled onto the Parma trial. J Clin Oncol 16:3264-3269, 1998

21. Gisselbrecht C, Schmitz N, Mounier N, et al: Rituximab maintenance therapy after autologous stem-cell transplantation in patients with relapsed $\mathrm{CD} 20^{+}$diffuse large B-cell lymphoma: Final analysis of the Collaborative Trial in Relapsed Aggressive Lymphoma. J Clin Oncol 30:4462-4469, 2012

22. Blay J, Gomez F, Sebban C, et al: The International Prognostic Index correlates to survival in patients with aggressive lymphoma in relapse: Analysis of the PARMA trial-Parma Group. Blood 92: 3562-3568, 1998

23. Martín A, Conde E, Arnan M, et al: R-ESHAP as salvage therapy for patients with relapsed or refractory diffuse large B-cell lymphoma: The influence of prior exposure to rituximab on outcome-A GEL/TAMO study. Haematologica 93:1829-1836, 2008

24. Thieblemont C, Briere J, Mounier N, et al: The germinal center/activated B-cell subclassification has a prognostic impact for response to salvage therapy in relapsed/refractory diffuse large B-cell lymphoma: A bio-CORAL study. J Clin Oncol 29: 4079-4087, 2011

25. Yang $Y$, Shaffer AL 3rd, Emre NC, et al: Exploiting synthetic lethality for the therapy of $A B C$ diffuse large B cell lymphoma. Cancer Cell 21:723737, 2012

\section{Affiliations}

Michael Crump, John Kuruvilla, and Vishal Kukreti, Princess Margaret Cancer Centre; Rena Buckstein and Kevin R. Imrie, Odette Cancer Centre and Sunnybrook Health Sciences Centre, Toronto; C. Tom Kouroukis, Jonathan Sussman, and Ralph M. Meyer, Margaret and Charles Juravinski Cancer Centre, Hamilton; Kang Howson-Jan, London Health Sciences Centre, London; Tara Baetz, Cancer Centre of Southeastern Ontario at Kingston General Hospital; Annette E. Hay, Marina S. Djurfeldt, Ralph M. Meyer, Bingshu E. Chen, and Lois E. Shepherd, NCIC Clinical Trials Group, Kingston; Leonard Kaizer, Credit Valley Hospital, Mississauga, Ontario; Stephen Couban and David A. MacDonald, Queen Elizabeth II Health Sciences Centre and Dalhousie University, Halifax, Nova Scotia; Morel Rubinger, Cancercare Manitoba, Winnipeg, Manitoba; Michael Voralia, Saskatoon Cancer Centre, Saskatoon, Saskatchewan; Harold J. Olney, Centre Hospitalier de l'Université de Montréal-Hopital Notre Dame, Montreal, Quebec; A. Robert Turner, Cross Cancer Institute, Edmonton, Alberta, Canada; Massimo Federico, University of Modena and Reggio Emilia, Modena; Nicola Di Renzo, Ospedale Vito Fazzi, Leece, Italy. 


\section{Appendix}

\section{List of Participating Countries, Groups, Centers, and Investigators}

Allan Blair Cancer Centre: H.I. Chalchal, M. Salim, I. Yaqoob; British Columbia Cancer Agency-Vancouver Cancer Centre: L. Sehn; Centre Hospitaliier Affilié Universitaire de Québec-Hopital Du Saint-Sacrement: G. Cantin, M. Bergeron, V. Laroche, J.F. Larouche; Centre Hospitalier de l'Université de Montré al-Hopital Notre-Dame: H.J. Olney, K. Belanger, G. Biron, N. Blais, D.Y. Lapointe, B. Lemieux, D. Soulieres, L. Yelle; Cancer Centre of Southeastern Ontario at Kingston General Hospital: T. Baetz, D. Lee, J.H. Matthews, G.J. Swain; CancerCare Manitoba: M. Rubinger, M.D. Seftel, J. Johnston, A. Maksymiuk, C. Olweny, B. Schacter, D. Szwajcer; Centre Hospitalier Universitaire de Sherbrooke: R. Leblanc, T. Alcindor, M. Lepine-Martin; Credit Valley Hospital: L. Kaizer, P.J. Anglin, M. Rother, J. Stakiw, Y. Zaretsky; Cross Cancer Institute: A.R. Turner, A. Belch, S. North, A.J. Reiman; Dr H. Bliss Murphy Cancer Centre: K. Grewal, G. Adams, K.A. Tompkins; Hopital Charles LeMoyne: P. Desjardins, S. Fox, J. Latreille, C. Sperlich; Hopital MaisonneuveRosemont: J. Beaudet, S. Cohen; Hopital du Sacre-Coeur de Montreal: G. Gaudet, B. Lesperance; Juravinski Cancer Centre at Hamilton Health Sciences: C.T. Kouroukis, A. Benger, S.R. Foley, G. Fraser, B. Leber, D. Marcellus, R. Meyer, M.R. Trus, P. Wasi; London Regional Cancer Program: K. Howson-Jan, R.M. Barr, I. Chin-Yee, R. Lohmann, J.E. Mangel, A. Xenacostas; Niagara Health System: B. Findlay, P.F.D. Hughes; Odette Cancer Centre Sunnybrook Health Sciences Centre: K.R. Imrie, N. Berinstein, R. Buckstein, M. Cheung, E. Piliotis, D. Spaner; Queen Elizabeth II Health Sciences Centre Nova Scotia Cancer Centre: S. Couban, D.R. Anderson, W. Hasegawa, A.K. Kew, D.A. MacDonald, S. Robinson; Saskatoon Cancer Centre: M. Voralia, W. Sabry Osman Ismail; St Michael's Hospital: R. Haq, L. Hicks, M. Trinkaus; The Moncton Hospital: S. Rubin, N. Abdel-Samad, H. Assi, A. Shaikh; Vitalite Health Network-Dr Leon Richard Oncology Centre: J.M. Vantelon; Thunder Bay Regional Health Science Centre: D. Vergidis, A. Chan, N. Laferriere; Tom Baker Cancer Centre: D. Stewart, N.J. Bahlis, D. Jenkins, M.L. Savoie; University Health Network-Princess Margaret Hospital: M. Crump, P.J. Anglin, J. Brandwein, A. Keating, J. Kuruvilla, V. Kukreti, I. Quirt, D.E. Reece. 